\title{
ENTREVISTA COM A PROFESSORA DOUTORA PAULA ROBERTA MIRANDA SOBRE O CENÁRIO EDUCACIONAL ATUAL NO ESTADO DO PARANÁ
}

\section{ENTREVISTA A LA LICENCIADA PAULA ROBERTA MIRANDA SOBRE LA SITUACIÓN ACTUAL DE LA EDUCACIÓN EN LA PROVINCIA DE PARANÁ}

Ligiane Aparecida da Silva1 $^{1}$
William Robson Cazavechia²

Paula Roberta Miranda ${ }^{3}$

A fim de contribuirmos para os estudos relacionados ao cenário educacional brasileiro na perspectiva das políticas educacionais, com destaque ao reformismo curricular e seus desdobramentos à formação e ao trabalho docente, entrevistamos Paula Roberta Miranda, professora pedagoga da rede estadual de ensino e professora colaboradora da Universidade Estadual de Maringá. Possui graduação em Pedagogia pela Universidade Estadual de Maringá (1999), Mestrado em Educação pela Universidade Estadual de Maringá (2007) e especialização em Gestão Educacional - Organização Escolar e Trabalho Pedagógico pela Universidade Estadual de Ponta Grossa (2011). Doutora em Educação pelo Programa de Pós-Graduação em Educação, na área de Políticas Públicas e Gestão educacional pela Universidade Estadual de Maringá (2017). Atuou como professora colaboradora das áreas de Didática, Prática de Ensino e Políticas Públicas e Gestão Educacional pela Universidade Estadual de Maringá, nos Departamentos Fundamentos da Educação e Teoria e Prática da Educação.

Como você avalia o processo de discussão, proposição e definição das políticas educacionais para a educação básica no Brasil na atualidade?

\footnotetext{
1 Universidade Federal de Mato Grosso do Sul, Brasil. E-mail: ligiane.silva@ufms.br

(i) https://orcid.org/0000-0002-3368-0415

2 Universidade Estadual de Maringá, Brasil. E-mail: wrcazavechia@gmail.com

(iD) https://orcid.org/0000-0002-8045-0823

${ }^{3}$ Rede Estadual de Ensino no estado do Paraná, Brasil. Universidade Estadual de Maringá. E-mail: paulinharmiranda@hotmail.com.

(i) https://orcid.org/0000-0003-1320-3774

- Informações completas da obra no final do artigo
} 
R. As políticas públicas se caracterizam por ações governamentais que buscam atender às reivindicações de um determinado grupo social. Antes de sua execução no contexto da prática onde essa política será experienciada, a mesma passa por várias instâncias, sofrendo alterações, ajustes e nem sempre alcançam um nível de igualdade e aceitação por parte daqueles que são os responsáveis por sua elaboração e execução, justamente por terem interesses antagônicos. Vem daí a não neutralidade das políticas públicas, pois são carregadas de interesses de sujeitos que nem sempre representam a maioria e suas demandas. Em relação às políticas para a educação básica, muito se tem discutido e avançado, se considerarmos a educação básica no percurso da história do Brasil. Em contexto histórico, vemos que todos os avanços que tivemos na educação brasileira, desde a alfabetização, ocorreram com vistas ao atendimento dos interesses da elite brasileira, ora para atender ao processo de industrialização e modernização do país, ora para atender a um contingente eleitoral, características que permanecem até o momento atual. A implementação de Leis, como a CF/88 e a LDB 9394/96, norteou os rumos da educação no país, designando responsabilidades aos entes federados e garantindo, ao menos na letra da Lei, o direito ao acesso e permanência na escola. No entanto, há que se destacar que, por estar inserida num campo conflituoso, desigual e marcado por interesses antagônicos, as políticas educacionais nunca atendem, de forma integral, justa, às demandas de quem elas se destinam. Isso porque não se considera a complexidade e as peculiaridades de um país como o Brasil, cuja educação não está na prioridade das pautas governamentais. Desse cenário caótico, o que se vê, então, é a elaboração e execução de políticas compensatórias em todas as esferas sociais, perpassando o campo da saúde, educação, moradia, por exemplo. No campo educacional, as políticas compensatórias circunscrevem-se ao básico: ler, escrever e contar, aprendizados que cumprem a função de minimizar os efeitos negativos que a redução ou a falta que um país de população alfabetizada faz em termos de aperfeiçoamento nas forças produtivas, aquisição de distribuição de riquezas e consequentemente de emprego. Apesar dos avanços que a nação brasileira já alcançou, vemos que ainda há um caminho longo a ser percorrido para a busca de uma educação de qualidade, justa, que garanta de fato a igualdade de acesso, permanência e de oportunidades no mundo do trabalho. Atualmente, as políticas educacionais necessitam de um olhar aprofundado e análise crítica para a compreensão de suas reais intenções para quem elas se destinam. Disto, depreende-se a 
necessidade de estudos aprofundados por parte daqueles que as colocarão em prática, a fim de não reproduzir os moldes de uma educação voltada para a adaptação ao mercado de trabalho, mas que, de fato, produza uma consciência crítica e mudança de posicionamento diante do cenário atual.

De que modo as escolas estaduais do Paraná estão se organizando para a adequação dos currículos à Base Nacional Comum Curricular (BNCC)?

R. No estado do Paraná, a adequação aos currículos está sendo organizada por meio da Secretaria Estadual de Educação que, desde o ano de 2020, vem elaborando o Currículo da Rede Estadual do Paraná (CREP). O estado do Paraná elaborou seu próprio currículo Estadual em consonância com a BNCC. Dessa forma, os docentes da rede estadual já elaboram seu Plano de Trabalho Docente de acordo com o CREP. Contam também com outro documento norteador, que são as Diretrizes Curriculares do estado do Paraná. Com vistas a colaborar com o professor nesse processo de adequação, foi inserido no Livro de Registro de Classe Online (RLCO), o CREP. No RLCO foi inserida uma aba PLANEJAMENTO, na qual o professor tem ali registrados os conteúdos estruturantes obrigatórios de sua disciplina para cada trimestre, os quais também já estão de acordo com a BNCC. Neste item, o professor tem a opção de "acrescentar mais conteúdos, se necessário", mas não pode excluir o que vem determinado pela Secretaria de Estado da Educação do Paraná (SEED/PR). Trata-se de uma forma de garantir que tais conteúdos sejam ministrados pelo professor.

Gostaríamos que comentasse sobre a participação dos profissionais da educação no processo de adequação desses currículos à Base. 0 envolvimento tem sido efetivo? Quais as dificuldades enfrentadas? Tem sido assegurado aos docentes as condições necessárias à sua atuação como sujeitos neste processo?

R. Em relação à participação dos profissionais da educação nesse processo de adequação curricular, destaco que foi aberto um processo de consulta pública, disponível em link no site da SEED para que todos pudessem ter acesso ao que estava sendo discutido e dessem sugestões quanto à ordem e prioridade de conteúdos a serem ministrados em todos os anos de ensino e em cada trimestre, de acordo com sua disciplina, bem como fizessem as alterações que julgassem necessárias. No entanto, enfrentamos 
algumas dificuldades no sentido de assegurar a autonomia do professor nessa escolha, pois quando a SEED implantou a Consulta Pública deste documento (CREP), o mesmo já veio com os conteúdos prefixados, não passíveis de alterações. Diante disso, a participação dos profissionais da educação foi mais tímida, podendo sugerir, dentro do CREP, apenas a ordem e a prioridade deste conteúdo, como por exemplo, ser ministrado no $1^{\circ}$, $2^{\circ}$ ou $3^{\circ}$ Trimestre. Nesse sentido, as possibilidades de assegurar a atuação do professor como protagonista do processo de uma aprendizagem significativa são os cursos de formação docente e sua atuação em sala de aula, espaços mais propícios para o trabalho com liberdade e capazes de desvelar as contradições que envolvem as políticas públicas educacionais, especialmente as que envolvem o currículo. Sabemos que o currículo não é neutro e, por isso mesmo, deve ser muito bem estudado e questionado. Atualmente, dispomos de um currículo educacional que prioriza números, resultados, em detrimento de um ensino humanizado e com qualidade. Como exemplo, podemos citar a reforma do Novo Ensino Médio e o próprio currículo da educação básica.

\section{Além de atuar como pedagoga na educação básica, você também leciona na} educação superior, em instituição pública. Como avalia a relação da BNCC com a atual estrutura e funcionamento dos cursos de licenciatura no país?

R. A BNCC trouxe consigo um rol de conteúdos comuns prefixados a serem ensinados desde a educação infantil até o Ensino Médio, com seus objetivos e prioridades a serem seguidas. A determinação e obrigatoriedade de elaboração deste documento já estavam previstas na CF/1988. Para além de uma base comum curricular, ou seja, conteúdos gerais a serem ensinados em todas as áreas de ensino, a inovação deste documento está nas dez competências gerais que ela traz, indicando detalhadamente a formação de um novo sujeito, a formação de um novo perfil de criança, jovem e adulto, capaz de atuar profissionalmente no mundo do trabalho de forma inovadora, criativa e inteligente. As dez competências gerais preconizam a formação integral de crianças, jovens e adultos. Estimula a formação de um sujeito criativo, inovador, capaz de apontar soluções para os inúmeros problemas que a sociedade moderna e tecnológica traz, com ética, rapidez e inteligência. Para além disso, cada área de conhecimento traz, também, de modo específico, como essas competências devem ser trabalhadas e desenvolvidas nos alunos por meio dos conteúdos de ensino. Por outro lado, as Universidades estaduais vêm 
passando por um processo de reestruturação curricular dos cursos de licenciatura, entre eles a pedagogia. A retirada ou a fusão de algumas disciplinas e o aumento de carga horária do curso é um indicativo de que o ensino superior também está sendo pressionado pelas instituições, a rever seu currículo, de modo a adequar-se às novas exigências do mundo do trabalho e do capitalismo. Sem destituir-se da ética, da ciência e do caráter humano, é necessário realizar estudos mais aprofundados nestes documentos que emanam do governo federal, seja para a educação básica ou ensino superior, no que diz respeito à organização curricular e à formação de professores. Ao analisarmos os documentos legais, vemos que, em sua essência, defendem a formação de um sujeito que esteja apto a atender às necessidades do capitalismo, às exigências dos novos postos de trabalho. A era tecnológica trouxe a flexibilização e a precarização do trabalho. Com isso, os índices de desemprego têm aumentado velozmente e os postos de trabalhos já não oferecem a estabilidade e a segurança de outrora, o que fomenta a competição desenfreada e a busca pelo lucro a qualquer custo. A massa da população, que depende do trabalho assalariado - formal ou informal - para sobreviver, fica à mercê dos grandes detentores do capital e dependente dos grandes centros de produção dos bens materiais necessários à manutenção de suas necessidades básicas de sobrevivência, como educação, saúde, moradia. Como um processo dialético e contraditório, as instituições superiores, na sua reorganização curricular, não podem preterir à crítica do modelo empresarial que se instalou no campo educacional. O tripé que forma as instituições de ensino superior - ensino, pesquisa e extensão - deve estar voltado para um ensino que, ao mesmo tempo, não esteja dissociado das transformações do mundo do trabalho, esteja preocupado e garanta uma prática docente capaz de desvelar os condicionantes da sociedade capitalista, apreendendo as mudanças que ocorrem em sua base material, seja no campo político, social, cultural e, principalmente, no campo econômico, mostrando, por meio dos conteúdos de ensino, a busca pelo lucro desmedido e suas trágicas consequências, entre elas o aumento dos problemas sociais graves, como o desemprego, a violência e o exponencial número de pessoas sobrevivendo abaixo da linha da pobreza. Dessa forma, é possível formar, nas novas gerações, sujeitos capazes de compreender essas contradições e posicionarem-se de modo crítico e consciente ante a elas. 
Para você, quais implicações já podem ser vislumbradas no cotidiano da escola como resultado das atuais políticas forjadas pelos reformadores empresariais da educação no país?

R. A educação básica, há tempos, vem passando por muitas mudanças. São vários documentos que compõem a Legislação educacional e que refletem diretamente no fazer pedagógico e no cotidiano da escola. As políticas públicas que vão desde a educação infantil até o ensino médio não têm garantido os princípios básicos da educação, como o acesso, permanência, aprendizagem e igualdade na oferta. É notório que almejamos uma educação básica de qualidade e acessível a todos, na qual crianças, jovens e adultos, de fato, aprendam os conteúdos que Ihes são ensinados, de modo a provocar mudanças significativas em suas vidas, que os índices de evasão e repetência diminuam e os índices de aprovação aumentem, porém, o que presenciamos na educação básica, em geral, é que todo o trabalho pedagógico vem sendo, gradativamente, orientado pelas Secretarias de Educação e Núcleos Regionais, a realizar um trabalho voltado para o replanejamento do trabalho docente, da melhoria da aprendizagem, com vistas a aumentar os índices de aprovação, mas também e, principalmente, para a busca de resultados nessa aprendizagem, aumento nos índices das avaliações internas e externas. Esse processo é feito tanto por meio tanto das orientações em documentos emanados das Secretarias como também por meio dos cursos de formação de professores que desconsideram as múltiplas realidades e peculiaridades existentes num país de tão grande extensão territorial. Em tempos de pandemia esse processo se intensificou, sob a justificativa de um ensino remoto, pelo qual se espera que todos tenham as mesmas oportunidades de acesso aos meios tecnológicos, como notebooks e internet, para realizar seus estudos de maneira satisfatória e garantir sua aprendizagem. Isso tem implicado de modo negativo nos resultados alcançados, na contramão de um processo de ensino e aprendizagem satisfatório, uma vez que aumentaram consideravelmente os índices de evasão, repetência e alunos fora da escola. Esse quadro tem nos mostrado que é urgente refletirmos sobre as políticas educacionais e seus objetivos finais que, infelizmente, querem conduzir um sistema educacional para a formação de massa, para atender aos desígnios do capital, retirandoIhes direitos fundamentais, como uma educação voltada para a emancipação dos indivíduos. 
Tendo como pauta ainda a discussão sobre a reformulação da BNCC, como você avalia as medidas tomadas para o enfrentamento da pandemia na educação do estado do Paraná? Quer dizer, tivemos uma discussão sobre um processo de reformulação em meio a uma situação de adaptação frente às circunstâncias impostas pela Covid-19. Qual sua avaliação sobre isso?

R. O que notamos nesse processo de medidas de enfrentamento à Covid-19 para o setor educacional é que houve e ainda há grande estímulo por parte de vários setores da sociedade para o retorno presencial dos alunos em todas as escolas do Paraná. A defesa para o retorno presencial ocorreu sob a justificativa da responsabilidade de uma articulação entre governo, instituições de ensino e sociedade, de que os outros setores (comércio, por exemplo) já estavam na ativa e que apenas as escolas públicas estavam fechadas. Percebemos aí uma ideologia dominante que quer garantir, a qualquer custo e preço, a manutenção de um posicionamento social e de poder. Sem conhecer a realidade objetiva das escolas públicas paranaenses, suas dificuldades em termos de falta de estrutura física e humana, sem conhecer a realidade da saúde de alunos, professores e demais profissionais da educação, foi determinado o retorno gradativo dos estudantes ao espaço escolar. Como forma de garantir o retorno presencial, as Trilhas de Aprendizagem (atividades que eram ofertadas para alunos de forma impressa), deixaram de ser postadas na plataforma Classroom, bem como as atividades diárias obrigatórias. O próximo corte será o de aulas via Meet, forçando, dessa forma, o retorno em cem por cento dos alunos para as instituições escolares. Com o corte das Trilhas de Aprendizagem e das atividades obrigatórias, os professores se veem obrigados a disponibilizar conteúdos para alunos que ainda se encontram em ensino remoto. Atualmente, estamos no modo ensino híbrido, com alguns alunos de forma online e a maioria dos alunos no modo presencial, processo este que não tem garantido uma aprendizagem significativa, uma vez que os alunos estão se adaptando ao retorno e o professor tendo que se reorganizar para dar aulas presenciais e, ao mesmo tempo, online. A meu ver, as adaptações curriculares que estão ocorrendo não estão contribuindo de modo algum para a melhoria da aprendizagem nem de sua qualidade, ao contrário, o que temos presenciado é um aceleramento de conteúdos, avaliações vindas da administração pública que buscam medir a qualidade do ensino ministrado e a aprendizagem adquirida. Vê-se claramente nesse contexto a busca por uma excelência na educação, todavia, é preciso estarmos alertas para a busca dessa excelência, uma vez que 
a excelência almejada não está, de fato, numa aprendizagem significativa, verdadeira, mas sim na busca de resultados, por números que não condizem com a realidade. Buscam, com isso, formar uma geração sem ensinar-Ihes os conteúdos mínimos a serem aprendidos para a construção de uma vida escolar significativa e dela obter êxito. Vemos, ao contrário, o estímulo para uma formação aligeirada, acelerada com vistas apenas a garantir um certificado de conclusão e assumir postos de trabalho que exigem o trabalho manual e não intelectual. Este último ficaria e está a cargo da iniciativa privada que oferece cursos rápidos, muitos deles na forma EAD, como garantias de conclusão de etapas de ensino, o que acaba se tornando um chamariz para aqueles que não se adaptaram ao ensino online, híbrido, ou que não têm perspectivas de retorno à escola ou, ainda, para ingressar de modo rápido no mercado de trabalho.

Observando alguns dados sobre a educação no país, sobretudo no que diz respeito à evasão escolar, evidenciamos um cenário preocupante, principalmente para os filhos da classe trabalhadora. A partir de sua experiência e vivência, como você tem observado esse cenário?

R. Discutir sobre a evasão escolar é algo complexo e nos remete à história da educação brasileira, na qual pode-se observar que, ao longo do desenvolvimento político, social, cultural e econômico do país, tivemos as descontinuidades ou nulidades de políticas públicas que levassem à frente os investimentos em educação básica. Se tomarmos apenas o fator econômico como exemplo, podemos deduzir que há uma relação direta com a questão da evasão escolar. Isto porque, a falta de investimentos, de recursos financeiros e tecnológicos de forma suficiente e adequada tem contribuído para que cada vez mais crianças, adolescentes e jovens deixem de frequentar a escola, especialmente os pertencentes às classes menos abastadas. Muitos deles não possuem condições financeiras para adquirir um celular com internet, notebook, requisito que hoje se tornou condição fundamental para frequentar a escola em tempos de pandemia. Outro fator é o deslocamento dessas crianças para a escola, visto que muitas não possuem condições financeiras para custear a passagem ou mudaram de endereço, necessitando de uma reorganização familiar. Com isso, a baixa frequência dos alunos tem feito parte da rotina das escolas paranaenses, sobretudo, nos municípios com menor autonomia financeira e nas famílias com menor poder aquisitivo. Alguns municípios, a exemplo de Maringá, 
disponibilizam o passe livre para os estudantes, mas devido à pandemia, o mesmo foi bloqueado e está sendo liberado de forma gradativa, tendo em vista a imposição do governo pelo retorno das aulas presenciais. A morosidade desse processo, de certa forma, também inviabiliza o estudante a frequentar regularmente as aulas. É inegável que a pandemia abalou de modo severo as estruturas da sociedade em todas as suas esferas. $O$ desemprego em escala global alterou a rotina de milhares de famílias, impondo uma reorganização familiar: filhos foram divididos entre a parentela para fugir da fome, famílias inteiras mudaram de cidade, de bairro, em busca de condições mínimas de sobrevivência, quais sejam, a alimentação, moradia, vestuário. Neste caso, podemos observar que a questão educacional fica em último lugar, na lista de prioridades da vida. Nessa reorganização familiar muitos de nossos jovens deixaram de frequentar o ensino médio em busca de trabalho. A busca pelo trabalho tem aí pelo menos duas razões importantes: a primeira delas é a questão da própria sobrevivência, pela qual muitos foram levados a buscar um trabalho para complementar a renda da família. A segunda, é que muitos jovens não utilizavam os recursos tecnológicos de que dispunham (quando tinham) como recurso pedagógico para ensino e aprendizagem. Saber usar as ferramentas tecnológicas para o prazer e a diversão são tarefas fáceis para a juventude, mas se tornaram um empecilho quando o assunto era organização sistemática do ensino. Isso deixou evidente o quanto nossos jovens necessitam cada vez de uma escolarização de qualidade, que lhes ofereça as oportunidades em igualdade em termos de acesso aos bens materiais e culturais. As dificuldades ali encontradas foram como barreiras para a participação de modo efetivo no ensino remoto, favorecendo, por consequência, a evasão escolar. Presenciamos também a evasão escolar na Educação de Jovens e Adultos, que teve sua proposta pedagógica alterada no início de 2020 pelo governo do estado. Alterou-se sua grade curricular, disponibilidade de disciplinas a serem cursadas pelo estudante, que passaram a ser oferecidas por módulos. Dessa forma, a flexibilidade que se tinha até então, de cursar mais livremente as disciplinas ao tempo disponível do estudante, foi substituída por uma grade "engessada" de disciplinas e módulos a serem cursados. Nesse processo de mudança e reconfiguração da EJA, muitos alunos não se adaptaram às novas formas de ensino e deixaram de frequentar a escola. Somado a isso, sabemos que o público que frequenta a EJA é formado também por alunos mais velhos que não foram ensinados a dominar as tecnologias, como celular e computador. Por não saberem usar celulares e computadores, 
muitos evadiram da escola, sob a promessa de retornarem quando a pandemia acabasse. Assim se manifestavam: "eu não sei usar o celular, eu não tenho computador", "eu gosto de aula com o professor em sala", "eu não aprendo dessa forma online", entre outros relatos. O resultado disso foi uma grande evasão escolar e um número alto de reprovação desses estudantes, gerando outros problemas sociais mais graves, como o desemprego em massa, pois não possuem os requisitos necessários para assumirem os postos de trabalho disponíveis no mercado. Posto isto, fica claro que é urgente repensar a educação básica no país, seus objetivos e a quem de fato ela se destina e tira proveito dela. As inúmeras políticas públicas e a legislação educacional em vigor para a educação básica não estão dando conta de alcançar seu verdadeiro objetivo, qual seja, atingir, com a máxima qualidade, o maior número de crianças, adolescentes, jovens e adultos que dela necessitam para se tornarem pessoas capazes de compreender as contradições postas pela sociedade capitalista, seus mecanismos de secundarização e disponibilidade de conteúdos, de currículo, especialmente aos pertencentes às classes trabalhadoras. Muitas dessas políticas estão apenas na letra da lei, mas quando são experenciadas e contextualizadas na prática escolar, vemos que muitas delas são políticas de focalização, as quais se limitam ao ler, escrever e contar, ou seja, formar pessoas, especialmente o público jovem para ocupar o mercado de trabalho, em postos de trabalho que demandam submissão e subserviência. Por outro lado, vemos que outras camadas da população educam seus jovens para as profissões de mando e com status quo privilegiado, inclusive em termos salariais.

\section{Mais uma vez tocando em questões sobre a pandemia em educação e sua} aparente e possível relação com o desmonte da educação pública no país, a partir de sua expertise, devemos ter em nosso horizonte essa reformulação do ensino como híbrido, remoto ou EAD como algo permanente?

R. Como afirmado na questão anterior, a pandemia abalou e mudou todas as estruturas sociais, seja no campo social, político, econômico, cultural, familiar, religioso, enfim, provocou mudanças drásticas jamais vistas e presenciadas, pelo menos nos últimos cinquenta anos. Se anteriormente a esse fenômeno global a educação brasileira, seja ela básica ou superior, já estava caminhando na esteira de uma educação autodidata, podemos supor que, de agora em diante, esse processo foi acelerado e dá mostras de que as 
políticas públicas estão endossando esse processo. O Novo Ensino Médio (NEM), homologado em 2017, terá implantação obrigatória em todas as escolas brasileiras a partir de 2022. Ancorado pela BNCC, terá disciplinas ofertadas no modo EAD. Para alunos do diurno a carga horária em EAD a ser cursada será de $20 \%$ e para alunos do noturno será de $30 \%$. No tocante à aprendizagem, é discutível, pois a pandemia mostrou o quanto os nossos jovens carecem de ensino presencial de qualidade e não estão preparados para o ensino na modalidade EAD. Contudo, as novas tendências educacionais disponíveis dos documentos oficiais e encaminhadas às escolas públicas nos mostram que este é um processo sem volta. O questionamento que se faz é que não há preparo nem suporte tecnológico nem físico para atender essa demanda imposta. O resultado nos números de IDEB e nas avaliações externas, como por exemplo, SAEP, Avaliações Paraná $1^{\text {a }}$ e $2^{\text {a }}$ edição (teremos até a $4^{\underline{a}}$ edição até o fim do ano letivo), aplicadas aos estudantes do $9^{\circ}$ ano, $3^{\circ}$ e $4^{\circ}$ ano do ensino médio, nos mostram que ainda precisamos caminhar muito para o alcance de resultados satisfatórios de aprendizagem em leitura, escrita, cálculo e resolução de problemas. Não somos contra o uso de tecnologias como ferramenta e suporte pedagógico e nem contra o autodidatismo no processo de ensino e aprendizagem, o que se questiona é a forma como isso vem sendo imposto às escolas brasileiras, especialmente no estado do Paraná, sem dar as mínimas condições para que essa aprendizagem aconteça com qualidade. Muitas escolas ofertam equipamentos de baixa qualidade para uso dos professores, notebooks com baixa potência, apresentando falhas, interrupções quase que diárias na transmissão de fibra ótica, não atingindo todo o espaço escolar, resultando em transmissões de aulas incompletas. Em pesquisa realizada sobre o enfrentamento à pandemia no requisito ensino híbrido, online, o estado do Paraná ficou à frente de estados como São Paulo e Rio de Janeiro, indicando o montante de milhões de reais que foram aplicados nesses recursos tecnológicos a fim de atender as escolas paranaenses. Contudo, notamos que as instalações físicas (prédios, salas) não estavam preparadas para receber tal tecnologia, pois faltavam reformas, equipamentos, ou seja, faltavam as condições básicas adequadas para essa implementação. Nota-se claramente a presença do Estado Mínimo, do fazer mais com menos para o setor público, enquanto o capital privado vem ganhando cada vez mais espaço na oferta de uma educação básica e superior com qualidade duvidosa. Nesse contexto, a precarização do trabalho docente fica em evidência. Contratos de professores temporários (PSS) cortados sem aviso prévio, 
redução do valor da hora aula, justificando tal redução na reforma administrativa e trabalhista. Com isso, os professores, para garantirem minimamente sua sobrevivência e de seus familiares, assumem o máximo de carga horária disponível, trabalhando em várias escolas ao mesmo tempo, causando, com isso, o adoecimento em escala geral, afastamentos, licenças, um quadro de desconforto e mal-estar docente. Nesse sentido, é possível afirmar que as mudanças que estão ocorrendo na esfera social, política e principalmente na econômica estão alterando drasticamente as formas de ver e fazer educação pública. Enquanto direito público, subjetivo, garantido pela Constituição Federal, a educação pública, seja ela básica ou superior, não deve ser relegada àqueles que dela necessitam, mas deve ser ofertada com a máxima qualidade, garantindo, no contexto da prática, o acesso, permanência e, principalmente, a conclusão dos estudos de crianças, adolescentes, jovens e adultos, desenvolvendo uma consciência crítica.

Uma questão de natureza mais ideológica, por assim dizer. Estamos convivendo diariamente com os apelos conservadores em educação, o que não é de hoje e já sabemos que a estratégia destes setores tem sido o alinhamento entre uma visão religiosa e a ação política que incide diretamente na promoção de valores absolutos. Como, em sua leitura, diante desse quadro, podemos, como estudantes, professores e pesquisadores, como comunidade de pais e servidores públicos, garantir uma educação democrática, gratuita, laica e de qualidade?

R. Temos sempre que nos lembrar que as políticas públicas em geral, e as educacionais, especificamente, estão em um campo de grandes disputas. São disputas pelo poder. Estão situadas num campo conflituoso, na defesa de interesses pessoais que nem sempre são o interesse da maioria da população que será a beneficiária direta daquela política. Outro fator a ser mencionado é que, na maioria das vezes, tais políticas não são elaboradas por pessoas relacionadas diretamente à educação básica pública, mas são pensadas e elaboradas por economistas, técnicos do MEC e de outros órgãos do governo que nunca estiveram à frente de uma escola pública ou nunca frequentaram uma instituição pública para perceber as suas lacunas em termos de acesso aos bens materiais e culturais daqueles que dela usufruem. Assim, umas das formas de garantia de uma educação democrática, gratuita, laica e de qualidade seria por meio da reelaboração crítica dos conteúdos de ensino que são ministrados em sala de aula. O conteúdo escolar é uma forma 
de linguagem, e ressignificar essa linguagem é abrir espaço para novas interpretações e reelaborações do conteúdo que está sendo ministrado. O professor tem aí uma excelente oportunidade de desvelar os condicionantes políticos e econômicos que imperam na sociedade capitalista e impedem a formação de uma consciência crítica por parte do estudante. É necessário desmistificar essa linguagem dominante que nos é imposta nos discursos oficiais, nos documentos legais e na Legislação educacional que tem defendido um currículo diferenciado para a classe trabalhadora e outro currículo para classes mais abastadas. Ao desvelarmos as contradições postas pelo capital, veremos aí a intencionalidade das políticas públicas, dos currículos, dos valores ideológicos incutidos que exaltam valores como o ter, ter mais dinheiro, ter mais poder, ter acesso diferenciado às diversas formas de conhecimento disponíveis na sociedade, e o ser, ser o melhor, ser o mais forte em detrimento de valores como igualdade de direitos, igualdade de acesso a uma educação de qualidade, igualdade no acesso à saúde de qualidade, moradia, segurança, elementos advindos do Poder Público. Compreender as mazelas da sociedade, como se dão suas formas de hierarquia entre as classes, divisão entre currículo real e currículo oculto, o que está escrito e a linguagem dominante que é disseminada, especialmente às classes populares, daria condições para a formação de uma consciência crítica, menos alienada. Portanto, dotados dessa criticidade, os sujeitos teriam a capacidade de elucidar os elementos ideológicos nele contidos e suas reais intenções e objetivos. Deste modo, poderiam fazer uma análise mais aprofundada e complexa dos fenômenos sociais que ocorrem em seu entorno e, partir daí, fazer interferências na prática social, interpretando a realidade em sua essência.

O que você recomendaria aos estudantes dos cursos de licenciatura que, em breve, atuarão nas escolas públicas brasileiras como docentes de diferentes áreas do conhecimento e até mesmo em espaços de gestão? O que podem esperar? Como poderão lidar com a realidade educacional que se configura e se consolida a cada dia em nosso país?

R. Minha recomendação é para que atuem sempre com muita responsabilidade em seu espaço de trabalho. Seja em sala de aula ou na gestão de uma instituição, que o façam com consciência crítica, no sentido de compreender as entrelinhas das políticas 


\section{ENSIN@UFMS 2021}

ISSN 2525-7056

educacionais e suas reais intenções, que possam ir além do aparentemente dado. As políticas educacionais expressas nos currículos não são neutras e trazem consigo uma forte intencionalidade de formar jovens para ocupar determinados postos de trabalho, com status quo menos reconhecido pela sociedade e com menor remuneração, logo, postos de trabalho que levam à submissão, à obediência e à aceitação dentro da esfera social em que está inserido, ao passo que outros jovens são socializados em escolas e com conteúdos de maior reconhecimento pela sociedade, logo, exercem trabalho de maior valor intelectual para ocupação de postos de liderança. Portanto, o olhar sobre o currículo, para esse professor ou gestor, deve ser aquele que não busque segregar ainda mais o que já está posto, mas que seja de ampliar o entendimento das políticas públicas que regem a educação, compreendendo as relações de trabalho dentro do sistema capitalista, tornandose conscientes da estrutura social.

\section{NOTAS}

\section{IDENTIFICAÇÃO DE AUTORIA}

Ligiane Aparecida da Silva. Doutora em Educação. Professora Adjunta da Universidade Federal de Mato Grosso do Sul, Campus de Três Lagoas, Três Lagoas, MS, Brasil.

E-mail: ligiane.silva@ufms.br

(iD) https://orcid.org/0000-0002-3368-0415

William Robson Cazavechia. Mestre em Educação. Doutorando do Programa de Pós-Graduação em Educação da Universidade Estadual de Maringá, Maringá, PR, Brasil

E-mail: wrcazavechia@gmail.com

(iD) https://orcid.org/0000-0002-8045-0823

Paula Roberta Miranda. Doutora em Educação. Professora Pedagoga da Rede Estadual de Ensino no estado do Paraná. Professora Colaboradora do Curso de Pedagogia da Universidade Estadual de Maringá. Maringá, PR, Brasil.

E-mail: email@email.br

(i) https://orcid.org/0000-0003-1320-3774

\section{AGRADECIMENTOS}

O presente trabalho foi realizado com apoio da Universidade Federal do Mato Grosso do Sul (UFMS).

\section{FINANCIAMENTO}

Não se aplica.

\section{CONSENTIMENTO DE USO DE IMAGEM}

Não se aplica.

\section{APROVAÇÃO DE COMITÊ DE ÉTICA EM PESQUISA}

Não se aplica.

\section{LICENÇA DE USO}


Autores mantêm os direitos autorais e concedem à revista ENSIN@ UFMS - ISSN 2525-7056 o direito de primeira publicação, com o trabalho simultaneamente licenciado sob a Licença Creative Commons Attribution (CC BY-NC-SA 4.0), que permite compartilhar e adaptar o trabalho, para fins não comerciais, reconhecendo a autoria do texto e publicação inicial neste periódico, desde que adotem a mesma licença, compartilhar igual.

\section{EDITORES}

Patricia Helena Mirandola Garcia, Eugenia Brunilda Opazo Uribe, Gerson dos Santos Farias.

\section{HISTÓRICO}

Recebido em: 04/09/2021 - Aprovado em: 02/11/2021 - Publicado em: 06/12/2021.

\section{COMO CITAR}

SILVA, L. A; CAZAVECHIA, W. R; MIRANDA, P. R. Entrevista com a Professora Doutora Paula Roberta Miranda sobre o Cenário Educacional Atual no Estado do Paraná. Revista ENSIN@ UFMS, Três Lagoas, v. 2, n. 6, p. 156-170. 2021. 